\title{
The oldest record of the Steller sea lion Eumetopias jubatus (Schreber, 1776) from the early Pleistocene of the North Pacific
}

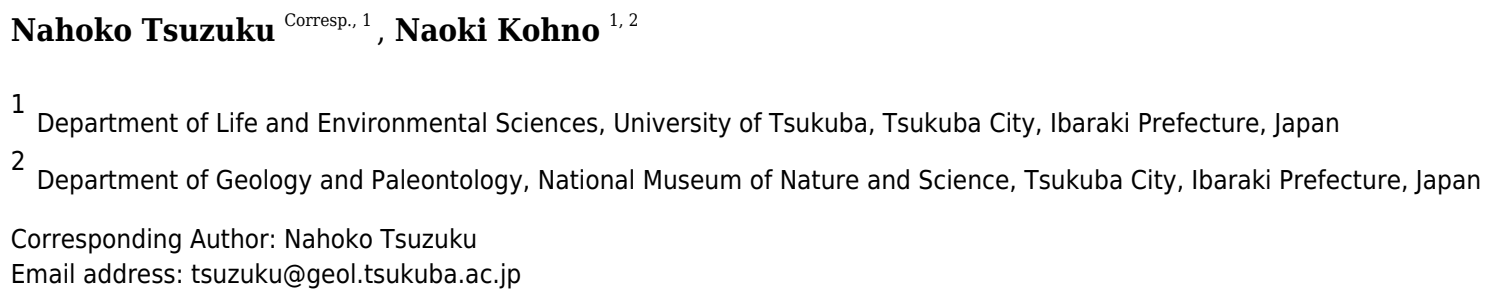

The extant genera of fur seals and sea lions of the family Otariidae (Carnivora: Pinnipedia) are thought to have emerged in the Pliocene or the early Pleistocene in the North Pacific. Among them, the Steller sea lion (Eumetopias jubatus) is the largest and distributed both in the western and eastern North Pacific. In contrast to the limited distribution of the current population around the Japanese Islands that is now only along the coast of Hokkaido, their fossil records have been known from the middle and late Pleistocene of Honshu Island. One such important fossils specimens has been recorded from the upper lower Pleistocene Omma Formation (ca. 1.36-0.83 Ma) in Kanazawa, Ishikawa Prefecture, Japan, which now bears the institutional number GKZ-N 00001 . Because GKZ-N 00001 is the earliest fossil having been identified as a species of the sea lion genus Eumetopias, it is of importance to elucidate the evolutionary history of that genus. The morphometric comparisons were made among 51 mandibles of fur seals and sea lions with GKZ-N 00001. As results of bivariate analyses and PCA based on 39 measurements for external morphologies with internal structures by CT scan data, there is almost no difference between GKZ-N 00001 and extant male individuals of E. jubatus. In this regard, GKZ-N 00001 is identified specifically as the Steller sea lion E. jubatus. Consequently, it is recognized as the oldest Steller sea lion in the North Pacific. About $0.8 \mathrm{Ma}$, the distribution of the Steller sea lion had been already established at least in the Japan Sea side of the western North Pacific. 
1 The oldest record of the Steller sea lion Eumetopias

2 jubatus (Schreber, 1776) from the early Pleistocene of 3 the North Pacific

4 Nahoko Tsuzuku ${ }^{1}$, Naoki Kohno1, 2

$5{ }^{1}$ Department of Life and Environmental Sciences, University of Tsukuba, Tsukuba City, Ibaraki

6 Prefecture, Japan

$7 \quad 2$ Department of Geology and Paleontology, National Museum of Nature and Science, Tsukuba

8 City, Ibaraki Prefecture, Japan

11 Corresponding Author:

12 Nahoko Tsuzuku 1

13 Department of Life and Environmental Sciences, University of Tsukuba, 1-1-1 Tennoudai,

14 Tsukuba, Ibaraki 305-8572, Japan

15 Email address: tsuzuku@geol.tsukuba.ac.jp 
16 The oldest record of the Steller sea lion Eumetopias

17 jubatus (Schreber, 1776) from the early Pleistocene of

18 the North Pacific

19

20

21

22

23

24

25

26

27

28

29

30

31

32

33

34

35

36

37

38

39

40

41

42

43

44

45

46

47

48

49

50

51

52

53

54

Nahoko Tsuzuku ${ }^{1}$, Naoki Kohno ${ }^{1,2}$

${ }^{1}$ Department of Life and Environmental Sciences, University of Tsukuba, Tsukuba City, Ibaraki Prefecture, Japan

${ }^{2}$ Department of Geology and Paleontology, National Museum of Nature and Science, Tsukuba City, Ibaraki Prefecture, Japan

Corresponding Author:

Nahoko Tsuzuku ${ }^{1}$

Department of Life and Environmental Sciences, University of Tsukuba, 1-1-1 Tennoudai, Tsukuba, Ibaraki 305-8572, Japan

Email address: tsuzuku@geol.tsukuba.ac.jp

\section{Abstract}

The extant genera of fur seals and sea lions of the family Otariidae (Carnivora: Pinnipedia) are thought to have emerged in the Pliocene or the early Pleistocene in the North Pacific. Among them, the Steller sea lion (Eumetopias jubatus) is the largest and distributed both in the western and eastern North Pacific. In contrast to the limited distribution of the current population around the Japanese Islands that is now only along the coast of Hokkaido, their fossil records have been known from the middle and late Pleistocene of Honshu Island. One such important fossils specimens has been recorded from the upper lower Pleistocene Omma Formation (ca. 1.36-0.83 $\mathrm{Ma}$ ) in Kanazawa, Ishikawa Prefecture, Japan, which now bears the institutional number GKZ-N 00001. Because GKZ-N 00001 is the earliest fossil having been identified as a species of the sea lion genus Eumetopias, it is of importance to elucidate the evolutionary history of that genus. The morphometric comparisons were made among 51 mandibles of fur seals and sea lions with GKZ-N 00001. As results of bivariate analyses and PCA based on 39 measurements for external morphologies with internal structures by CT scan data, there is almost no difference between GKZ-N 00001 and extant male individuals of E. jubatus. In this regard, GKZ-N 00001 is identified specifically as the Steller sea lion E. jubatus. Consequently, it is recognized as the oldest Steller sea lion in the North Pacific. About $0.8 \mathrm{Ma}$, the distribution of the Steller sea lion had been already established at least in the Japan Sea side of the western North Pacific.

\section{Introduction}

The extant pinnipeds of the order Carnivora are divided into three families, the Otariidae, the Odobenidae, and the Phocidae (e.g., Berta et al., 2018). Among them, the otariids are distributed 
55

56

57

58

59

60

61

62

63

64

65

66

67

68

69

70

71

72

73

74

75

76

77

78

79

80

81

82

83

84

85

86

87

88

89

90

91

92

93

94

mostly in the Pacific Ocean and composed of fur seals and sea lions. Sea lions are generally large in body size; in particular, the Steller sea lion (Eumetopias jubatus) in the North Pacific is the largest among them. In contrast to the relatively limited distribution of the current population of the Steller sea lion in Japan, which is now only around Hokkaido (Loughlin et al., 1984; 1987), their distribution during the Pleistocene is thought to be relatively broad, because their mandibular and tooth fossils have been known from the Pleistocene of Honshu Island. One such important fossil specimens has been recorded from the upper lower Pleistocene Omma Formation (ca. $1.36-0.83 \mathrm{Ma}$ ) in Kanazawa, Ishikawa Prefecture, Japan, which bears the institutional number GKZ-N 00001 (Figs. 1, 2; Kaseno, 1951; Shikama, 1953; Mitchell, 1968). In October 1946, a right mandibular fossil (i.e., GKZ-N 00001) was collected by the late Dr. Yoshio Kaseno (then Kanazawa University) and third year students of the Biological Department, Kanazawa Higher Normal School, Ishikawa Prefecture, Japan. The specimen came from the upper part of the Omma Formation at a road cutting south of Gosyo village (now Gosyo Town), northeastern end of Kanazawa City, Ishikawa Prefecture, central Japan. While Kaseno (1951) identified GKZ-N 00001 tentatively as a species of "Allodesmus" which is an extinct pinniped known from the Miocene of the North Pacific, Shikama (1953) pointed out that GKZ-N 00001 might belong to E. jubatus (E. jubata at that time). Later, Mitchell (1968) also suggested that GKZ-N 00001 be studied further before being unequivocally identified as conspecific with E. jubatus. Currently, the specific identification of GKZ-N 00001 is still ambiguous and in controversy (e.g., Kohno \& Tomida, 1993; Barnes et al., 2006) and has not been confirmed yet. At the time when GKZ-N 00001 was found, the Omma Formation had been considered to be Pliocene in age, but it turned out to be early Pleistocene (ca. 1.36- $0.83 \mathrm{Ma}$ ) based on the calcareous microfossil stratigraphy (Takayama et al., 1988). The extant genera in the Otariidae including Eumetopias are considered to be branched off at the end of the Pliocene (Repenning \& Tedford, 1977), and the oldest fossil record of extant otariid genera is known from the late Pliocene to the early Pleistocene (Berta \& Deméré, 1986; Kohno \& Yanagisawa, 1997). These studies suggest that the early Pleistocene that may also correspond to the emergence of the genus Eumetopias is important time to elucidate the evolutionary history of the otariids. Therefore, highlighting the meaningfulness of proper identification of GKZ-N 00001 is meaningful.

\section{Materials \& Methods}

In order to compare fossil specimens with modern taxa, the morphometric analyses are performed using 51 mandibles of fur seals and sea lions: 12 male and 12 female individuals of the Steller sea lion E. jubatus, three male and 10 female individuals of the Northern fur seal Callorhinus ursinus, 10 male and one female individuals of the Japanese sea lion Zalophus japonicus, two male individuals of the Odysseus sea lion Proterozetes ulysses, and GKZ-N 00001 (Table 1, Data S1). A total of 21 landmarks are defined with reference to the previous morphometric research (Berta \& Deméré, 1986; Isono, 1998; Adam \& Berta, 2002; Brunner, 2004; Boessenecker, 2011; Kienle \& Berta, 2015), and a total of 39 measurements are taken using a digital caliper to the nearest $0.01 \mathrm{~mm}$ (Fig. 3, Tables 2, 3, S1). 
95 Based on these measurements, bivariate analyses and principal component analysis (PCA) are 96 performed. PCA is implemented in R 3.5.1 ( $R$ Core Team, 2018). In addition, the mandibles are 97 observed with the micro-computed tomographic scanner using Microfocus CT, TXS320-ACTIS 98 at the National Museum of Nature and Science, Tokyo, Japan.

99

100

101

102

103

104

105

106

107

108

109

110

111

112

113

114

115

116

117

118

119

120

121

122

123

124

125

126

127

128

129

130

131

132

133

134

\section{Systematic Paleontology}

\section{MAMMALIA Linnaeus, 1758}

CARNIVORA Bowditch, 1821

PINNIPEDIA Illiger, 1811

OTARIIDAE Gill, 1866

Included Genera: [extant genera] Arctocephalus Cuvier, 1826; Arctophoca Peters, 1866; Callorhinus Gray, 1859; Eumetopias Gill, 1866; Neophoca Gray, 1866; Otaria Peron, 1816; Phocarctos Peters, 1866; Zalophus Gill, 1866. [extinct genera] Eotaria Boessenecker \& Churchill, 2015; Pithanotaria Kellogg, 1925; Thalassoleon Repenning \& Tedford, 1977; Hydrarctos (de Muizon, 1978) Berta \& Deméré, 1986; Proterozetes Barnes et al., 2006 (after Berta \& Churchill, 2011; Velez-Juarbe, 2017).

Emended Diagnosis of Family: [Crown Otariidae (C. ursinus, northern sea lion clade, and southern otariid clade)] single rooted P3, P4, p2, and p4. Pronator teres insertion positioned on the proximal $40 \%$ of the radius. Secondary shelf of the sustentaculum of the calcaneum developed as a wider shelf (modified from Churchill et al., 2014).

\section{EUMETOPIAS Gill, 1866}

Included Species: Only the extant species Eumetopias jubatus (Schreber, 1766).

Remarks: Horikawa (1981) described a partial skeleton including some isolated cheek teeth as the holotype of a new species in the genus, i.e., Eumetopias ojiyaensis, based on comparisons mainly of the upper incisor and canine with a female of E. jubatus. However, the characters he mentioned (e.g., overall similarity of teeth, condition of accessory cusps on the molar etc.) are plesiomorphic or nondiagnostic for the sea lions and unavoidable the potential identification of the holotype to a species of other sea lion genera within the Otariidae because of its incompleteness. We consider E. ojiyaensis a nomen dubium and suggest a temporary pending on both generic and specific identification for its holotype until much better specimens at least including the mandible will be obtained from the type locality or the same formation.

Diagnosis of Genus: As for the species.

\section{Eumetopias jubatus (Schreber, 1776)}

Emended Diagnosis: Eumetopias jubatus is the largest species in body size (about $3.3 \mathrm{~m}$ in males) among the family Otariidae. The upper and lower canines are large in males, particularly at the apical ends of roots that are almost evergrowing (less so in females). The mandible is long and the angle between the horizontal and ascending rami is large (about 130-140 degree) in contrast to the smaller angle of less than 130 degree in other genera and species. The masseteric 
135 fossa is deep and long, especially in older individuals. Postcanines are unicuspid with well136 developed labial and lingual cusples at the base (modified from Brunner, 2004).

137 Dental formula: $3 / 2,1 / 1,4 / 4,1 / 1$.

138 Referred specimen: GKZ-N 00001, incomplete right dentary with right lower canine, left p2,

139 left and right p4, left P4 and right M1; collected by the late Yoshio Kaseno (then Kanazawa

140 University) and third year students of the Biological Department, Kanazawa Higher Normal

141 School, in October 1946. Now this specimen is stored at the Graduate School of Natural Science

142 and Technology, Kanazawa University (GKZ).

143 Locality of referred specimen: GKZ-N 00001 was found at a road cutting south of Gosyo

144 Town, north-eastern end of Kanazawa City, Ishikawa Prefecture, Japan. The geographical

145 coordinate is $36^{\circ} 34$ ' 51 “ North Latitude, $136^{\circ} 40^{\prime}$ '59” East Longitude. Currently, no

146 outcrop remains there.

147 Formation and Age: GKZ-N 00001 was yielded from the upper part of the Omma Formation. It

148 is consisted of homogeneous silty fine-grained sandstone in bluish color, from which many

149 fragmentary remains of molluscs such as Acila, Pecten, Venericardia, Myodora, Cardium, and

150 Diplodonta have been collected (Kaseno, 1951). The geologic age of the Omma Formation

151 corresponds to the late early Pleistocene (ca. 1.36-0.83 Ma) based on the calcareous microfossil

152 stratigraphy (Takayama et al., 1988). The depositional environment of the Omma Formation is

153 thought to be cold temperate water within $0-30 \mathrm{~m}$ in depth, on a shoreface or inner shelf, the

154 upper part of the upper shallow-sea zone, on the basis of the habitat preferences of molluscan

155 fossils collected from a bed slightly higher than the horizon of GKZ-N 00001 (Tsuzuku,

156 2018MS).

157 Associated Mammalian Fossils: Matsuura (1996) reported some metacarpals and phalanges of

158 possibly otariid pinnipeds. In addition, many cetacean and some sirenian fossils have also been

159 found from the same formation (Matsuura \& Nagasawa, 2000), although these have not yet been

160 described in detail.

161

162 Description

163 Mandible (Fig. 1): GKZ-N 00001 is a right mandible consisting of almost complete horizontal

164 ramus and broken coronoid process. The $\mathrm{c} 1$ and $\mathrm{p} 2$ are in place on the horizontal ramus. Both

165 left and right $\mathrm{p} 4$ are also preserved as isolated teeth. In addition, isolated left P4 and right M1 are

166 also preserved, suggesting that the skull as well as the left mandible might also be preserved at

167 the time of its discovery. Based on the robustness of the mandible and the size of the canine

168 relative to the length of the cheek toothrow that reaches $42 \%$, GKZ-N 00001 is definitely a

169 male. The horizontal ramus is long and thick, and has unparallel dorsal and ventral margins. The

170 anterior border of the horizontal ramus (the portion anterior to the incisors and the canine) is

171 expanded anterolaterally. The bone surface of the ramus is rough, but not vascularized. The

172 mandibular symphysis is unfused, elliptical in shape, and upturned anteriorly. The posterior

173 border of the symphysis extends below the anterior margin of $\mathrm{p} 2$. The genial tuberosity is very

174 small and located below p3. There are eight distinct mental foramina on the lateral surface of the

Peer] reviewing PDF | (2020:02:45925:1:1:NEW 30 Jun 2020) 
175 horizontal ramus. They are nearly rounded or ellipsoidal in form, with the diameter varying from

176

177

178

179

180

181

182

183

184

185

186

187

188

189

190

191

192

193

194

195

196

197

198

199

200

201

202

203

204

205

206

207

208

209

210

211

212

213

214

about 3 to $15 \mathrm{~mm}$. The anterior mental foramen is located beneath i 3 on the anterior margin of the horizontal ramus and is slit-like. Its length is about $15 \mathrm{~mm}$ and width is $4 \mathrm{~mm}$. The middle mental foramina are located between $\mathrm{p} 1$ and $\mathrm{p} 3$ on the mid portion of the horizontal ramus, and the most anterior elliptical and large hole is located beneath $\mathrm{p} 1$ with the diameter of $11 \mathrm{~mm}$ in major axis and $6 \mathrm{~mm}$ in minor axis. The second middle mental foramen is located beneath $\mathrm{p} 1$ and p2 and rounded in outline, with a diameter of $11 \mathrm{~mm}$. The third middle mental foramen is located beneath $\mathrm{p} 2$ on the mid portion of the horizontal ramus and is very large ellipsoidal in form. Its major axis is about $11 \mathrm{~mm}$ and minor is $6 \mathrm{~mm}$. The fourth middle mental foramen is located between $\mathrm{p} 2$ and $\mathrm{p} 3$, and is rounded in outline and $6 \mathrm{~mm}$ in diameter. The fifth middle mental foramen is located between $\mathrm{p} 3$ and $\mathrm{p} 4$ and is rounded in outline and $7 \mathrm{~mm}$ in diameter. The sixth middle mental foramen is located beneath $\mathrm{p} 4$ and is the smallest rounded hole and $6 \mathrm{~mm}$ in diameter. The posterior mental foramen is located beneath the posterior margin of $\mathrm{m} 1$ and is the rounded in outline and $9 \mathrm{~mm}$ in diameter. Almost all of them are directed anterodorsally, but the fifth and sixth forward mental foramina are directed posterodorsally. Most of the coronoid process is broken away. The ventral margin of the masseteric fossa is preserved on the lateral surface and is relatively deep and large in area. It is anteroposteriorly broad at the base of the coronoid process. The pterygoid process is broken at the ventral margin on the medial surface of the ascending ramus. The mandibular foramen is large, with a diameter of $7 \mathrm{~mm}$. The digastric prominence is very weak. The mandibular condyle is broken away, but the breakage suggests that it was elevated slightly high above the level of the cheek toothrow. The dentary has two incisors, one canine, four premolars and one molar. The dentition converges medially from $\mathrm{p} 1$ until $\mathrm{p} 3$ and diverges laterally from $\mathrm{p} 4$ until $\mathrm{m} 1$. Each tooth is moderately spaced, and the diastema between the $\mathrm{c} 1$ and $\mathrm{p} 1$ is slightly wider than others.

Teeth (Figs. 1, 2): The i2 and i3 are missing, but their alveoli are preserved anterior to the $\mathrm{c} 1$. Both are single rooted. The $\mathrm{c} 1$ is robust and conical. Its apex is abraded. The pulp cavity of $\mathrm{c} 1$ is widely opened. The $\mathrm{p} 1$ is missing, but its alveolus is preserved on the dentary. It is single rooted. The $\mathrm{p} 2$ is preserved in place and lanceolate in form with sharp cutting edge. It has a highly developed lingual cingulum, and a well developed accessory cusp is located mesially at the base of the crown. The $\mathrm{p} 3$ is fallen away, but its alveolus is preserved, which is single rooted and bilobed in outline. The left and right $\mathrm{p} 4$ are preserved as detached isolated teeth. The crown is lanceolate with blunt cutting edge. It has poorly developed lingual cingulum with well developed accessory cusp. Their roots are bilobate and vertical to the long axis of the crown. The $\mathrm{m} 1$ is missing, but its alveolus indicates that the $\mathrm{m} 1$ is distinctly double rooted.

The detached isolated $\mathrm{P} 4$ is preserved. The crown is tall and conical, and bluntly pointed at the tip with single cusp. There is no sharp cutting edge with a cingulum at the base of the crown. There is no well developed accessory cusp. It is bilobate single rooted, and its root is oblique to the long axis of the crown. The M1 is also preserved as a detached tooth. It has conical crown, blunt cutting edge, undeveloped cingulum, and slightly developed accessory cusp at the base of

Peer) reviewing PDF | (2020:02:45925:1:1:NEW 30 Jun 2020) 
215 crown. It is double rooted and oblique to the long axis of the crown. These roots are curved

216 inward and forward strongly.

217

218 Results of Morphometric analyses

219 Bivariate analyses

220 GKZ-N 00001 is almost as large as the mandible of male Steller sea lion and larger than that of

221 other known sea lions including the recently extinct Japanese sea lion and the middle Pleistocene

222 Odysseus sea lion (Tables 2, 3, S1). In addition to the differences of their absolute sizes, the $\mathrm{p} 1$

223 of the Odysseus sea lion is extremely smaller than other cheek teeth on the mandible (Poust \&

224 Boessenecker, 2017), and the consequent gradient of cheek tooth sizes against the cheek

225 toothrow length are quite different to that of GKZ-N 00001 and of the Steller sea lion. All these

226 results rule out that GKZ-N 00001 belongs to the Odysseus and/or Japanese sea lions in size of

227 the mandible and to the Odysseus sea lion in proportion of the cheek teeth. Given these

228 differences, a taxonomic definition for GKZ-N 00001 as a species of Eumetopias is at least

229 warranted. However, given the high amount of morphological variation within species of sea

230 lions necessitates additional morphological approach to classify GKZ-N 00001 more clearly. For

231 these reasons, we made morphometric analyses for GKZ-N 00001 with E. jubatus and at least all

232 the North Pacific sea lions including extinct taxa mentioned above.

233 We performed 39 measurements among 21 landmarks on each mandible of 51 individuals from

234 GKZ-N 00001 and extant taxa including 13 Northern fur seals and 24 Steller sea lions and

235 extinct taxa including 11 Japanese sea lions and two Odysseus sea lions in total (Fig. 3, Tables 2,

$2363, \mathrm{~S} 1)$. These variables were correlated heuristically to each other. Then, highly correlated

237 bivariates were considered to evaluate taxonomic significance for the mandibular fossil. As the

238 results of the analyses, three bivariates by total of six parameters were distinctive among species;

239 the depth of the horizontal ramus at $\mathrm{c} 1$ versus the mesiodistal diameter of $\mathrm{c} 1$, the depth of the

240 horizontal ramus at $\mathrm{p} 1$ versus that of the same portion at $\mathrm{m} 1$, and the major axis of the

241 mandibular symphysis versus the minor axis of the same portion (Fig.4). They were also

242 distinctively differentiated between males and females. In all bivariates, GKZ-N 00001 was

243 plotted slightly larger than the $95 \%$ confidence interval of the Ordinary Least Square regression

244 lines of the sampled male individuals of E. jubatus.

245 These results suggest that the difference between GKZ-N 00001 and the male E. jubatus is only

246 a little and that the former could be included in the variation of the latter. In fact, the E. jubatus

247 samples used in this study are individuals collected from around Hokkaido for a purpose to

248 prevent damage to the fisheries, so the individuals tend to be slightly smaller in the average of

249 their body size than that of the original population. For this reason, GKZ-N 00001 that is plotted

250 slightly larger than the $95 \%$ confidence interval as E. jubatus could be interpreted as a large male

251 individual of E. jubatus.

252

253 Proportion of the canine root 
254 Regarding GKZ-N 00001, the greatest mesiodistal and buccolingual diameters of the lower 255 canine root measured from CT image is $50.3 \mathrm{~mm}$ and $27.6 \mathrm{~mm}$ respectively (Fig. 5, Table 4). 256 Accordingly, the ratio of the buccolingual to mesiodistal diameter expressed as a percentage is 257 54.9. Kohno \& Tomida (1993) suggested that the same ratio of the lower canines expressed as a 258 percentage for the males of E. jubatus ranged from 51.6 to 61.8 (the mean is 56.6; Table 4). 259 Therefore, GKZ-N 00001 is included within the range of male E. jubatus in regard to the canine 260 proportion.

261

262

263

264

265

266

267

268

269

270

271

272

273

274

\section{Discussion}

276 GKZ-N 00001 has lanceolate, simplified cheek teeth, and lacks m2. This condition is recognized 277 to be a synapomorphy of the crown Otariidae (King, 1983; Boessenecker \& Churchill, 2015;

278 Velez-Juarbe, 2017). In addition, the overall size of this mandible is included within the range of 279 those in the largest sea lion; i.e., the Steller sea lion E. jubatus. Also a result of morphometric 280 analyses for the size and proportion of the mandible for GKZ-N 00001 with extant species of a 281 fur seal and sea lions such as the Northern fur seal, the Japanese sea lion and the Steller sea lion 282 distributed in the western North Pacific suggest that GKZ-N 00001 is included in a range of $E$. 283 jubatus and that it is inferred to be a male individual. Therefore, GKZ-N 00001 is distinctively 284 identifiable to the extant species of the Steller sea lion E. jubatus. Although GKZ-N 00001 is 285 slightly larger than male individuals sampled from the Recent population, it is at the moment 286 uncertain whether this is simply the size variation among individuals of the same species or a 287 potential implication of larger average size in the early Pleistocene population of the same 288 species. At present, we consider that GKZ-N 00001 was just a large individual of $E$. jubatus until 289 the multiple specimens of mandibles are obtained from the same and/or younger geochronologic 290 formations.

291 Apart from the size difference, all the cheek teeth of the extant specimens of E. jubatus are single 292 or bilobate single rooted. However, the alveolus for $\mathrm{p} 4$ of GKZ-N 00001 is bilobate single rooted 293 in condition, and $\mathrm{m} 1$ is strongly bilobate and apically double rooted (Figs.7, S1). Although this 
294 condition is not seen in the variation of extant specimens of E. jubatus, $\mathrm{m} 1$ root is always 295 bilobate and its degree is strongly variable and successive among them (Fig. S1). Because the 296 otariids (and stem taxa of odobenids in the Otarioidea) have a process that the cheek tooth 297 condition is gradually changed from double rooted to single rooted to be homodont dentition 298 during their evolution (Berta \& Deméré, 1986; Boessenecker, 2011; Velez-Juarbe, 2018), the 299 bilobate condition of $\mathrm{p} 4$ and the apically double rooted condition of $\mathrm{m} 1$ on GKZ-N 00001 are 300 considered to be plesiomorphic conditions in a series of transition to the homodonty within a

301

302

303

304

305

306

307

308

309

310

311

\section{Conclusions}

313 The mandibular fossil (GKZ-N 00001) from the lower Pleistocene Omma Formation (0.8 Ma) is 314

\section{0}

331

332

333 same species as a parallel phenomenon during their evolution. Accordingly, the condition of the cheek tooth roots on GKZ-N 00001 would also simply be a primitive feature for the lineage of the Steller sea lion.

Finally, the recognition of GKZ-N 00001 as the oldest record of Eumetopias jubatus could also be important also for the molecular phylogenetics (see also Parham et al., 2012). Because only the subfamilial divergence estimates among the pinnipeds had calibrated based on fossil records of crown pinnipeds (e.g., Yonezawa et al., 2007), and because the oldest fossil record of

Eumetopias had not been traced back only until the late Pleistocene, it could be considered the geologic age of GKZ-N 00001 as a good calibration point to improve divergence estimates between Eumetopias and its closest genus Zalophus and also of the crown Otariidae. specifically identified as $E$. jubatus based on the morphometric analyses. Previously, the oldest record of E. jubatus was from the upper Pleistocene of North America (Kohl, 1974; Whitmore \& Gard, 1977; Barnes et al., 2006), so GKZ-N 00001 from the upper lower Pleistocene (ca. 0.8 $\mathrm{Ma}$ ) is now recognized as the oldest record of E. jubatus. This implies that the distribution of the Steller sea lion was already established at about by $0.8 \mathrm{Ma}$ in the western North Pacific and at least southerly in the Sea of Japan.

\section{Institutional Abbreviations}

DCIFC: Daté City Institute of Funkawan Culture, Daté City, Hokkaido, Japan

GKZ-N: Geological collection, Kanazawa University, Kanazawa. New series. Japan

HM: $\quad$ Hokkaido Museum, Sapporo, Hokkaido, Japan

NMNS-KK: The late Kinjiro Kubota collection, Department of Geology and Paleontology, National Museum of Nature and Science, Tsukuba, Japan

NMNS-M: Mammalogical collections, Department of Zoology, National Museum of Nature and Science, Tsukuba, Japan

\section{Acknowledgements}

We thank Robert G. Jenkins (Kanazawa University), Yuko Tajima (National Museum of Nature and Science), Hiroshi Usiro and Yuji Soeda (Hokkaido Museum), Tomoya Aono (then Daté City Institute of Funkawan Culture, now Tohoku University of Art and Design), Yukihito Nagaya 
334 (Daté City Institute of Funkawan Culture), and Gen Nakamura (Tokyo University of Marine 335 Science and Technology, Tokyo, Japan) for permitting us to use their collections and providing 336 us with working space at respective institutes. We also thank Chisako Sakata (NMNS) for CT 337 scanning specimens for this study. We are grateful to Katsuo Sashida (then University of

338 Tsukuba, now Mahidol University), Sachiko Agematsu and Kohei Tanaka (University of 339 Tsukuba), and Yasunari Shigeta (National Museum of Nature and Science, and University of 340 Tsukuba) for their useful advice, discussion and generous encouragement during the course of 341 this study.

342

\section{References}

344 Adam PJ, Berta A, 2002. Evolution of prey capture strategies and diet in the Pinnipedimorpha 345 (Mammalia, Carnivora). Oryctos 4: 83-107.

346 Barnes LG, Ray CE, Koretsky IA, 2006. A new Pliocene Sea Lion, Proterozetes ulysses

347 (Mammalia: Otariidae) from Oregon, U. S. A. Mesozoic and Cenozoic Vertebrates and 348 Paleoenvironments; Tributes to the career of Prof. Dan Grigorescu, 55-57.

349 Berta A, Churchill M, 2011. Pinniped taxonomy: review of currently recognized species and 350 subspecies, and evidence used for their description. Mammal Review 42: 207-234.

351 Berta A, Churchill M, Boessenecker RW, 2018. The Origin and Evolutionary Biology of 352 Pinnipeds: Seals, Sea Lions, and Walruses. Annual Review of Earth and Planetary Sciences 46: $353203-228$.

354 Berta A, Deméré TA, 1986. Callorhinus gilmorei n. sp., (Carnivora: Otariidae) from the San 355 Diego Formation (Blancan) and its implications for otariid phylogeny. Transactions of the San 356 Diego Society of Natural History 21: 111-126.

357 Boessenecker RW, 2011. New records of the fur seal Callorhinus (Carnivora: Otariidae) from 358 the Plio-Pleistocene Rio Dell Formation of Northern California and comments on otariid dental 359 evolution. Journal of Vertebrate Paleontology 31: 454-467.

360 Boessenecker RW, Churchill M, 2015. The oldest known fur seal. Biology Letters 11: 36120140835.

362 Bowditch TE, 1821. An Analysis of the Natural Classification of Mammalia for the Use of 363 Students and Travellers. Paris, J. Smith.

364 Brunner S, 2004. Fur seals and sea lions (Otariidae): Identification of species and taxonomic 365 review. Systematics and Biodiversity 1: 339-439.

366 Churchill M, Boessenecker RW, Clementz MT, 2014. Colonization of the Southern

367 Hemisphere by fur seals and sea lions (Carnivora: Otariidae) revealed by combined evidence 368 phylogenetic and Bayesian biogeographical analysis. Zoological Journal of the Linnean 369 Society, 172, 200-225.

370 Cuvier F, 1826. Phoque. Dicliotmaire des Sciences Naturelles 39: 540-559.

371 Gill T, 1866. Prodrome of a monograph of the pinnipedes. Proceedings Essex Institute 372 Communications 5: 3-13. 
373 Gray JE, 1859. On the sea bear of Foster, the Ursus marinus of Steller, Aerctocephalus ursinus

374 of authors. Proceedings of the Zoological Society of London 27: 102-103.

375 Gray JE, 1866. Notes on the skulls of sea-bears and sea-lions (Otariadae) in the British

376 Museum. Annals and Magazine of Natural History Series 3 18: 228 - 237.

377 Horikawa H, 1981. On a new fossil sea-lion from the Uonuma Group (Plio-Pleistocene), Ojiya, 378 Niigata Prefecture, Central Japan. Earth Science 35: 159-178.

379 Illiger JKW, 1811. Prodromus Systematis Mammalium et Avium Additis Terminis

380 Zoographicis Utriusque Classis, Eorumque Versioe Germanica. Berolini. C. Salfield.

381 Isono T, 1998. Development of the external morphology, skull and canines of Steller sea lions.

382 Biosphere Conservation 1: 149-160.

383 Kaseno Y, 1951. Pliocene pinniped remains from Kanazawa, Ishikawa Prefecture, Japan.

384

Transactions and Proceedings of the Palaeontological Society of Japan, New Series (2): 57 -

385

64.

386

Kellogg R, 1925. New pinnipeds from the Miocene diatomaceous earth near Lompoc,

387

California. Contributions to Palaeontology from the Carnegie Institution of Washington 348: 71

388 -95 .

389

Kienle SS, Berta A, 2015. The better to eat you with: The comparative feeding morphology of

390 phocid seals (Pinnipedia, Phocidae). Journal of Anatomy 228: 396-413.

391

King JE, 1983. Seals of the World $2^{\text {nd }}$ Edition. Ihaca, NY: Cornell University Press.

392

Kohl RF, 1974. A new Late Pleistocene fauna from Humbert County, California. Veliger 17:

393 $211-219$.

394

Kohno N, Tomida Y, 1993. Marine mammal teeth (Otariidae and Delphinidae) from the Early

395 Pleistocene Setana Formation, Hokkaido, Japan. Bulletin of the National Museum of Nature and Science Series C (Geology and Paleontology) 19: 139-146.

397

Kohno N, Yanagisawa Y, 1997. The first record of the Pliocene Gilmore fur seal in the western 398 North Pacific Ocean. Bulletin of the National Museum of Nature and Science Series C (Geology

399 and Paleontology) 23: 119-130.

400

Kubota, K, Nagasaki F, Matsumoto K, Tsuboi M, 1961. Histological studies on the growth

401

402 layers in the maxillary canines of fur seals as an indicator of age. Part1. the teeth at the age of

403 one to nine years. The Bulletin of Tokyo Medical and Dental University 8: 261 - 285.

404

Linnaeus C, 1758. Systema nature per regna tria synonymis, locis. Tomus 1. (10th edition). 824pp. Stockholm: Laurentius Salvius.

405 Loughlin TR, Rugh DJ, Fiscus CH, 1984. Northern sea lion distribution and abundance: 1956406 80. Journal of Wildlife Management 48: 729-740.

407 Loughlin TR, Perez MA, Merrick RL, 1987. Eumetopias jubatus. Mammalian Species (283): $408 \quad 1-7$.

409 Matsuura N, 1996. Vertebrate fossils from the Omma Formation of Kanazawa area, Ishikawa 410 Prefecture, Japan. HGI Report: (5), 55-87. 
411 Matsuura N, Nagasawa K, 2000. Fossil cetaceans from the distribution area of the Omma

412 Formation in Kanazawa, Ishikawa Prefecture, Japan. Nihonkai Cetology: (10), 37-47.

413 Mitchell ED Jr, 1968. The Mio-Pliocene pinniped Imagotaria. Journal of the Fisheries

414 Research Board of Canada 25: 1843 - 1900.

415 Muizon C de, 1978. Arctocephalus (Hydractos) lomasiensis, subgen, nov. et nov. sp., un nouvel

416 Otariidae du Mio-Pliocene de Sacaco (Perou). Bulletin de l'Institut Francais d'Etudes Andines

417 7: 168-188.

418 Parham JF, Donoghue PCJ, Bell CJ, Calway TD, Head JJ, Holroyd PA, Inoue JG, Irmis

419 RB, Joyce WG, Ksepka DT, Patane JSL, Smith ND, Tarver JE, Tuinen M van, Yang Z, 420 Angielczyk KD, Greenwood JM, Hipsley CA, Jacobs L, Makovicky PJ, Muller J, Smith

421 KT, Theodor JM, Warnock RCM, 2012. Best practices for justifying fossil calibrations.

422 Systematic Biology 61: 346-359.

423 Peron F, 1816. Voyage de decouvertes aux terres Australes, execute par ordre de Sa Majeste

424 l'Empereur et Loi, sur les corvettes le Geographe, le Naturaliste, et la goelette le Casuarina, 425 pendant les annees. 1800, 1801, 1802, 1803, et 1804. Imprimerie Imperiale. Paris, 2, $1-471$.

426 Peters W, 1866. Über neue oder ungengend bekannte Flederthiere (Vampyrops, Uroderma,

427 Chiroderma, Ametrida, Tylostoma, Vespertilio, Vesperugo) und Nager (Tylomys, Lasiomys).

428 Monatsberichte der Königlich Preussischen Akademie der Wissenschaften zu Berlin 1867: 392

$429-411,2$ pls.

430 Poust AW, Boessenecker RW, 2017. Mandibles of the sea lion Proterozetes ulysses from the

431 middle Pleistocene Port Orford Formation of Oregon. Journal of Vertebrate Paleontology :

432 e1317637 (8 pages).

433 R Core Team, 2018. $R$ : A language and environment for statistical computing. R Foundation for

434 Statistical Computing, Vienna, Austria. https://www.R-project.org/.

435 Repenning CA, Tedford RH, 1977. Otarioid seals of the Neogene. Geological Survey

436 Professional Paper 992: 1-93.

437 Schreber JCD, 1776. Die Saugethiere in Abbildungen nach der Natur, mit Beschreibungen.

438 Leipzig: (7), 1774-1846.

439 Shikama T, 1953. On a fossil remain of sea-lion, Eumetopias (?) kishidai n. sp. from Japan.

440 Science Reports of the Yokohama National University, Series 2 (2): 10-16.

441 Takayama T, Kato M, Kudo T, Sato T, Kameo K, 1988. Calcareous microfossil

442 biostratigraphy of the uppermost Cenozoic formations distributed in the coast of the Japan Sea

443 - Part2: Hokuriku sedimentary basin - . Journal of the Japanese Association for Petroleum

444 Technology 53: 10-27.

445 Tsuzuku N, 2018MS. Stratigraphy and Paleontology of the Pleistocene Omma Formation

446 Distributed in Kanazawa, Ishikawa Prefecture, Japan. University of Tsukuba.

447 Velez-Juarbe J, 2017. Eotaria citrica, sp. nov., a new stem otariid from the "Topanga"

448 Formation of Southern California. PeerJ 5: e3022. https://doi.org/10.7717/peerj.3022. 
449 Velez-Juarbe J, 2018. New data on the early odobenid Neotherium mirum Kellogg, 1931, and 450 other pinniped remains from the Sharktooth Hill Bonebed, California. Journal of Vertebrate 451 Paleontology 38: e1481080 (14 pages).

452 Whitmore FC Jr, Gard LM Jr, 1977. Steller's Sea Cow (Hydrodamalis gigas) of Late 453 Pleistocene age from Amchitka, Aleutian Islands, Alaska. Geological Survey Professional 454 Paper 1306: IV+19+[19].

455 Yonezawa T, Kohno N, Hasegawa M, 2009. The monophyletic origin of sea lions and fur seals 456 (Carnivora; Otariidae) in the Southern Hemisphere. Gene 441: 89-99. 


\section{Figure 1}

Right mandibular fossil of Eumetopias jubatus (GKZ-N 00001)

(A) lateral aspect (B) medial aspect (C) dorsal aspect

Photo credit: Nahoko Tsuzuku 
(A)
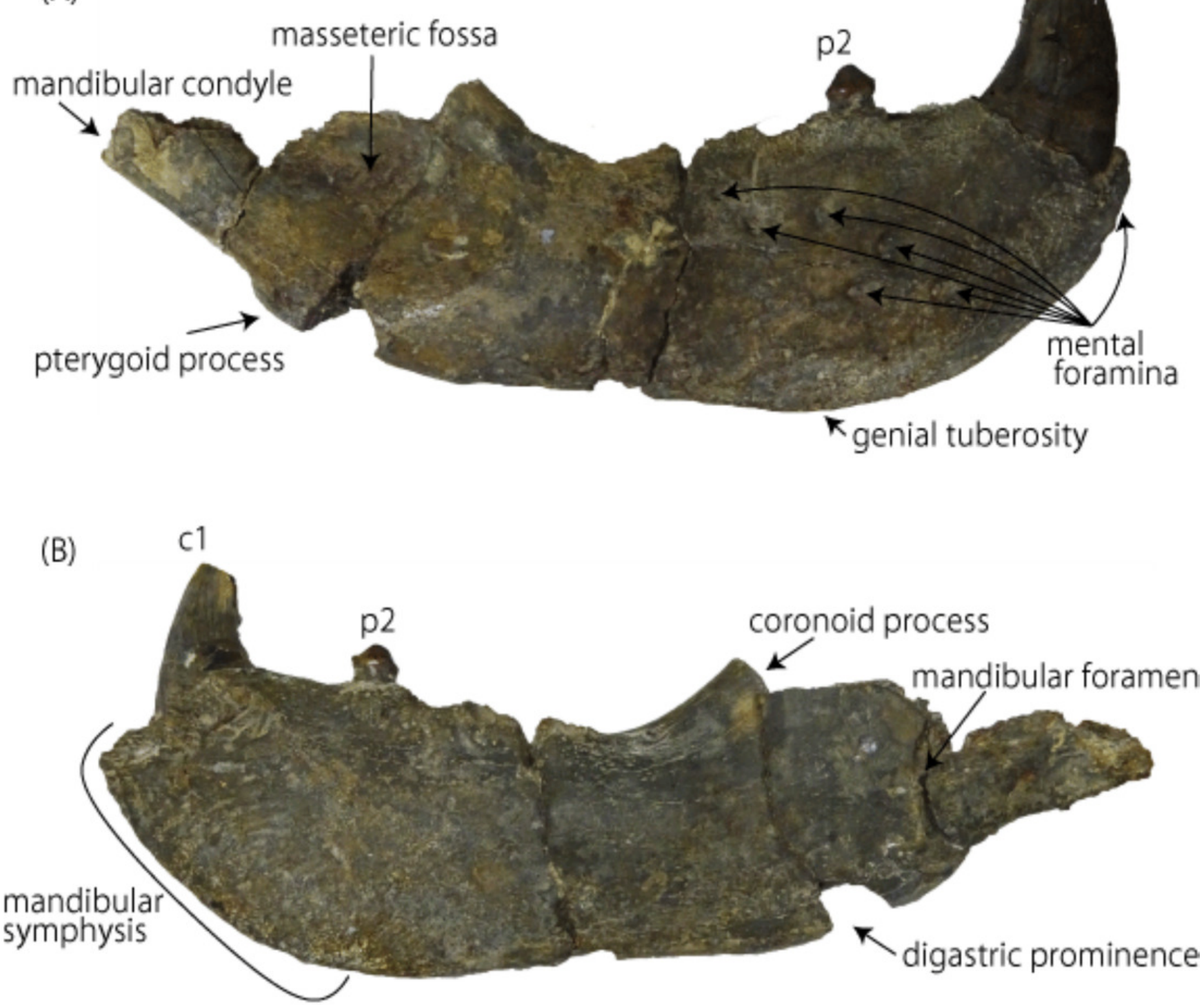

(C)

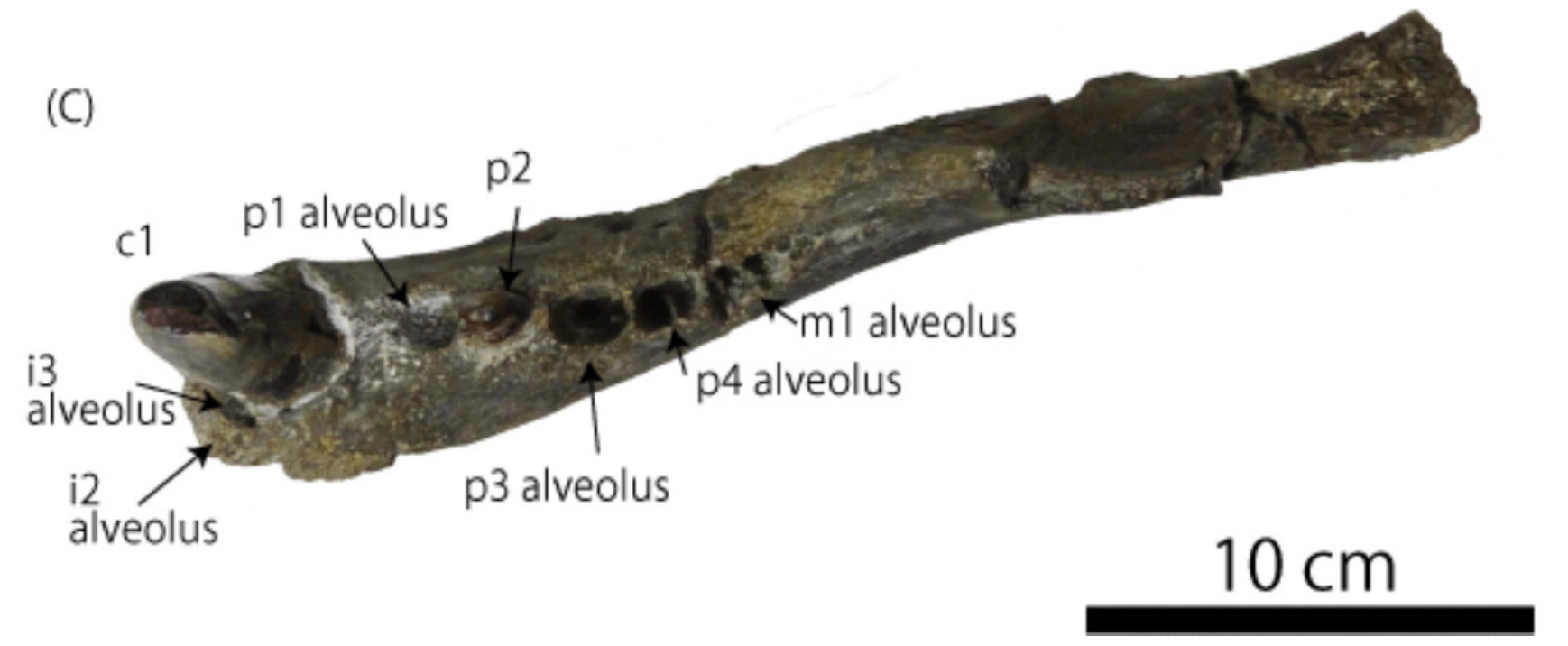




\title{
Figure 2
}

\section{Detached molariform teeth of GKZ-N 00001}

\begin{abstract}
(A) lingual view of left p4 (B) buccal view of left p4 (C) occlusal view of left p4 (D) lingual view of right p4 (E) buccal view of right p4 (F) occlusal view of right p4 (G) lingual view of left P4 (H) buccal view of left P4 (I) occlusal view of left P4 (J) lingual view of right M1 (K) buccal view of right M1 (L) occlusal view of right M1

Photo credit: Nahoko Tsuzuku
\end{abstract}


A

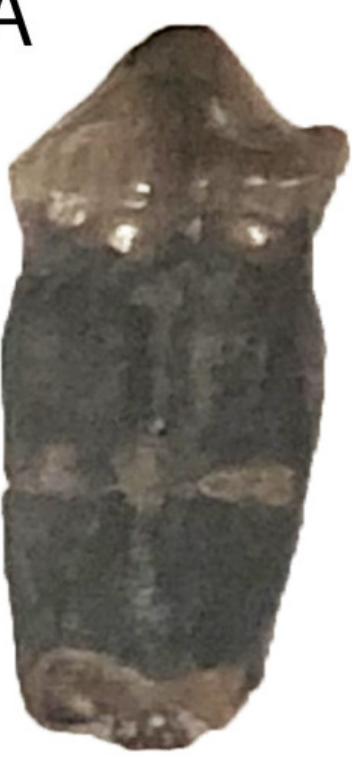

B

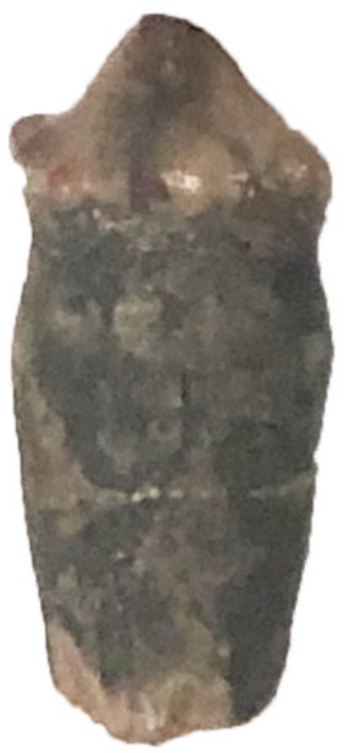

C

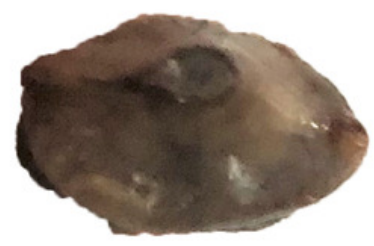

D

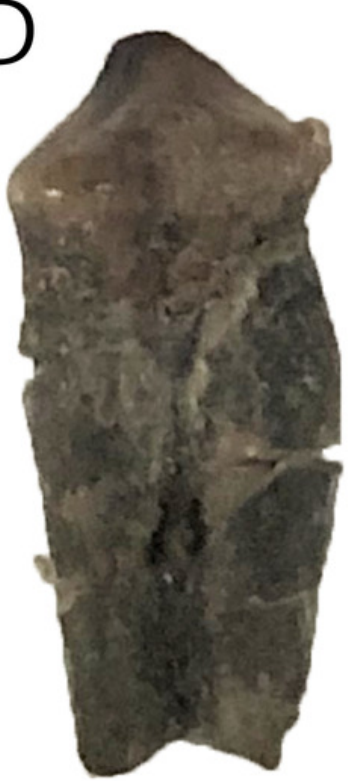

E

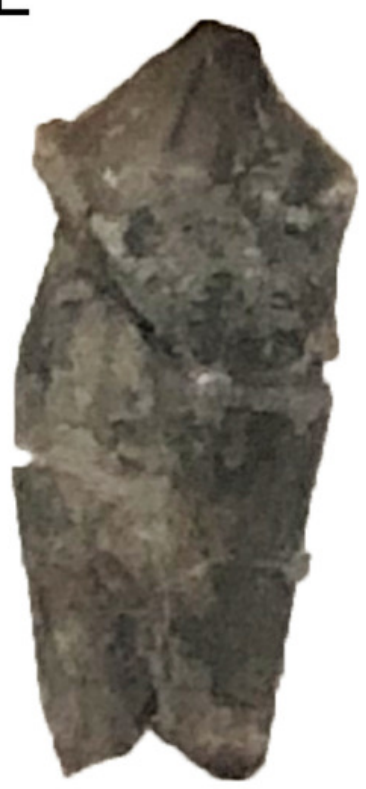

F

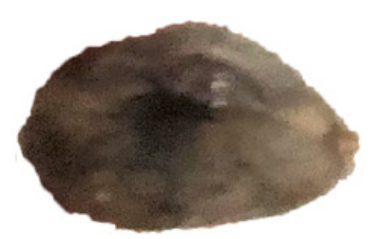

G

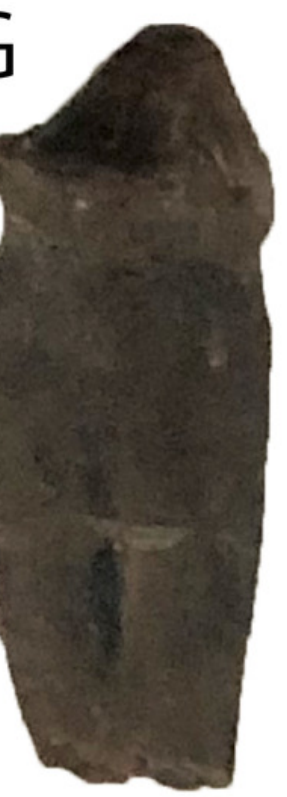

$\mathrm{H}$
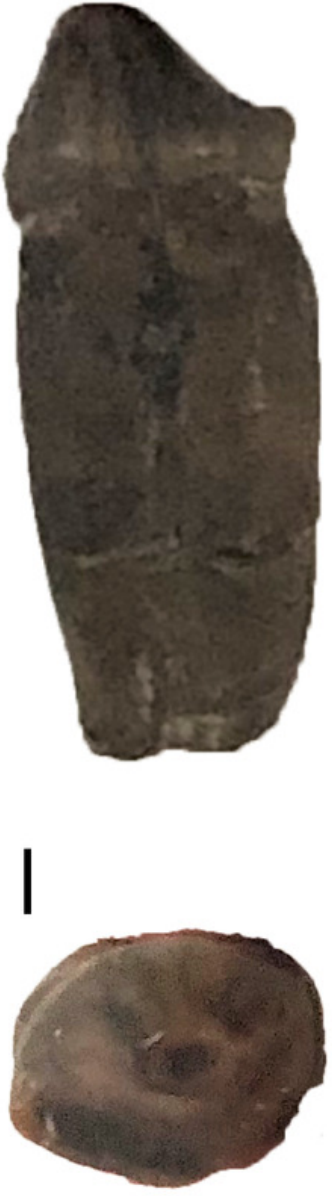

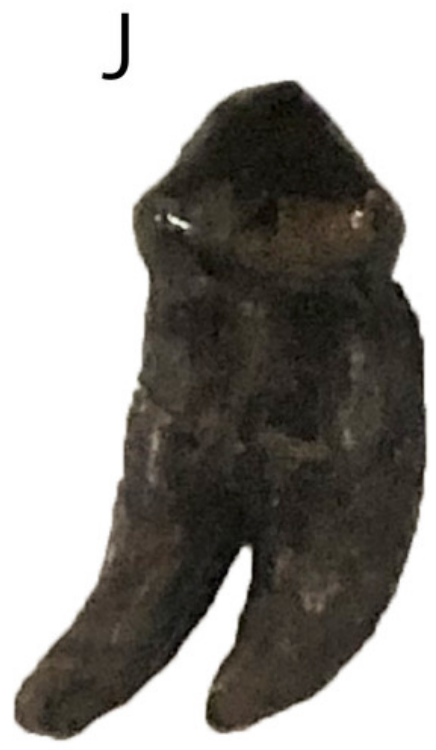

K

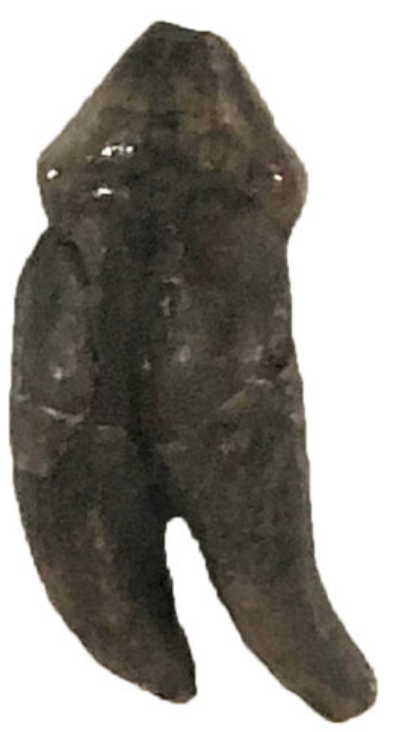

$\mathrm{L}$

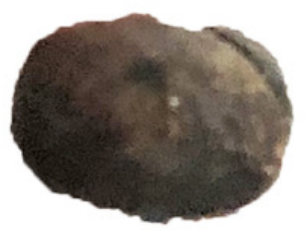

$2 \mathrm{~cm}$ 
Figure 3

Mandibular landmarks and measurements used in this study

(A) lateral aspect (B) medial aspect (C) dorsal aspect

Photo credit: Nahoko Tsuzuku 
(A)

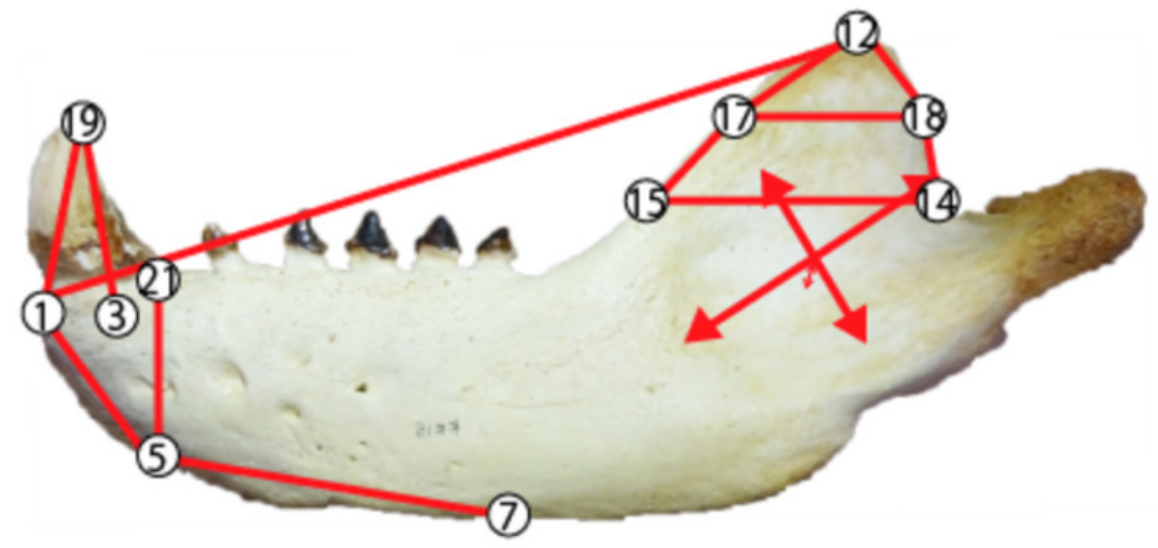

(B)

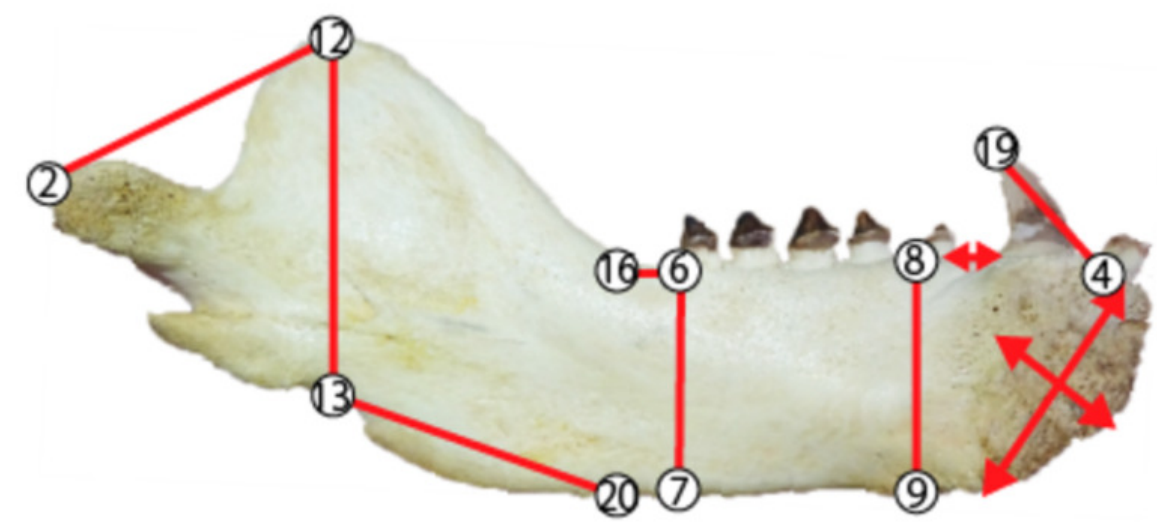

(C)

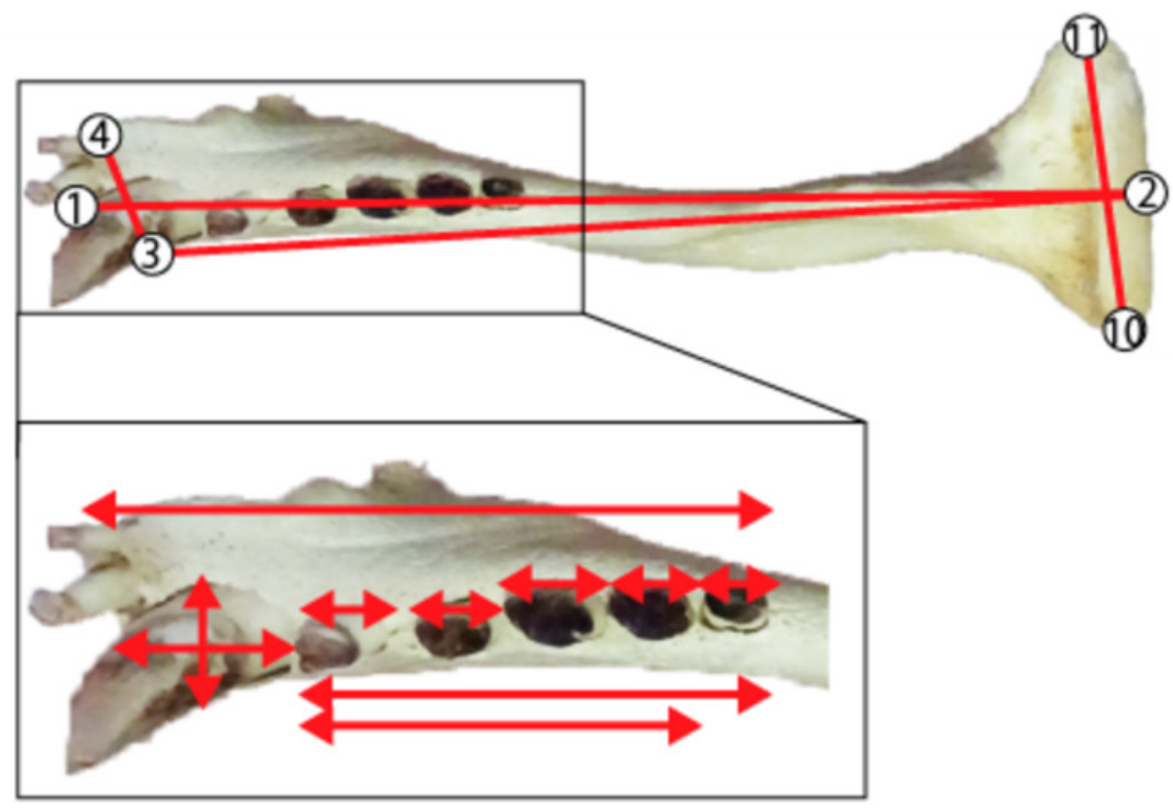

$10 \mathrm{~cm}$ 


\section{Figure 4}

Result of bivariate analyses

(A) depth of horizontal ramus at c1 (I) versus the mesiodistal diameter of cl (AF); (B) depth of horizontal ramus at $\mathrm{pl}(\mathrm{J})$ versus that of same portion at $\mathrm{ml}(\mathrm{K})$; (C) major axis of mandibular symphysis (X) versus minor axis of same portion (Y). Pink polygons show $95 \%$ confidence intervals of the regression lines. Characters in parentheses correspond to measurement points (Table S1). 
(A)

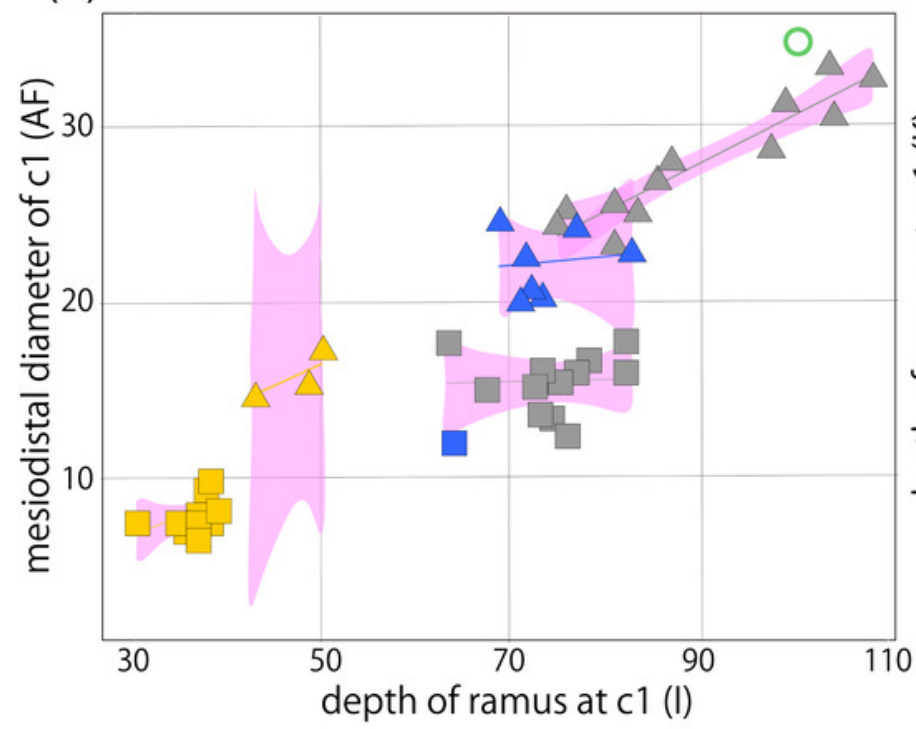

(C)

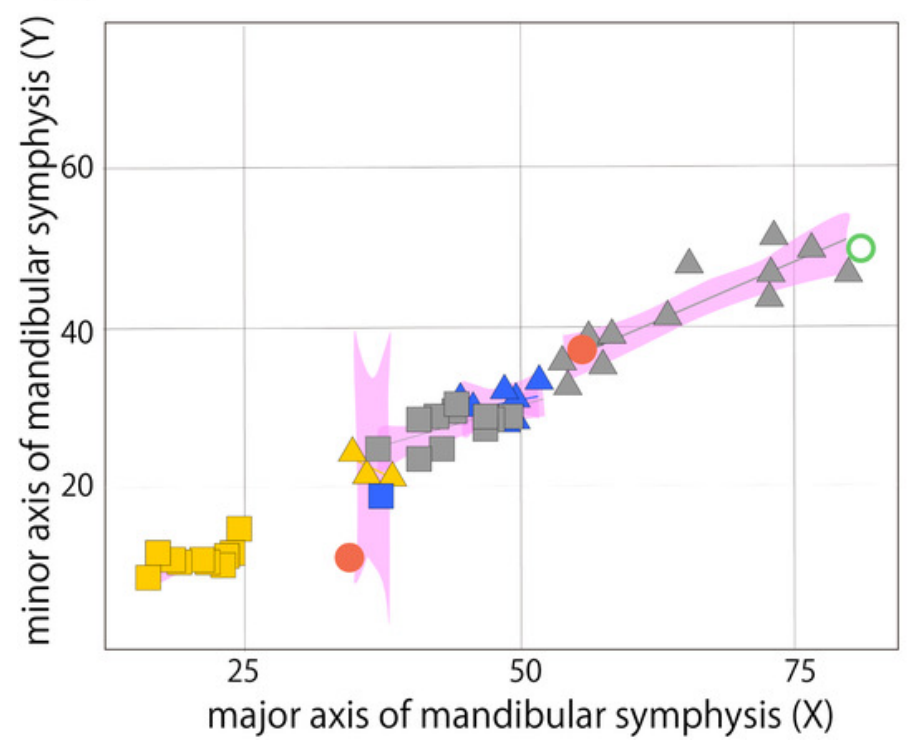

(B)

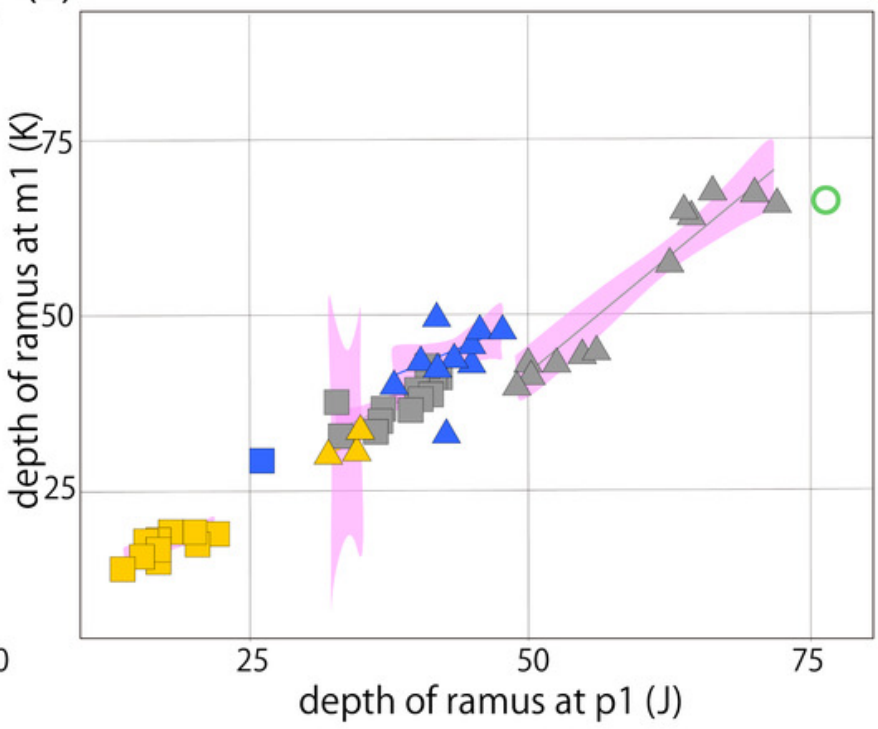

$\Delta$ E. jubatus $[\mathrm{male}] \quad \square$ E. jubatus $[\mathrm{female}]$

$\triangle$ C. ursinus $[\mathrm{m}] \quad \square$ C.ursinus $[\mathrm{f}]$

$\Delta$ Z.japonicus $[\mathrm{m}] \quad$ Z. japonicus $[\mathrm{f}]$

○ GKZ-N $00001 \quad$ P. ulysses

$(\mathrm{mm})$ 


\section{Figure 5}

A micro CT image, showing the maximum length and width of lower canine root of GKZN 00001.

Yellow lines indicate: (A) mesiodistal diameter (B) buccolingual diameter Photo credit: Naoki Kohno

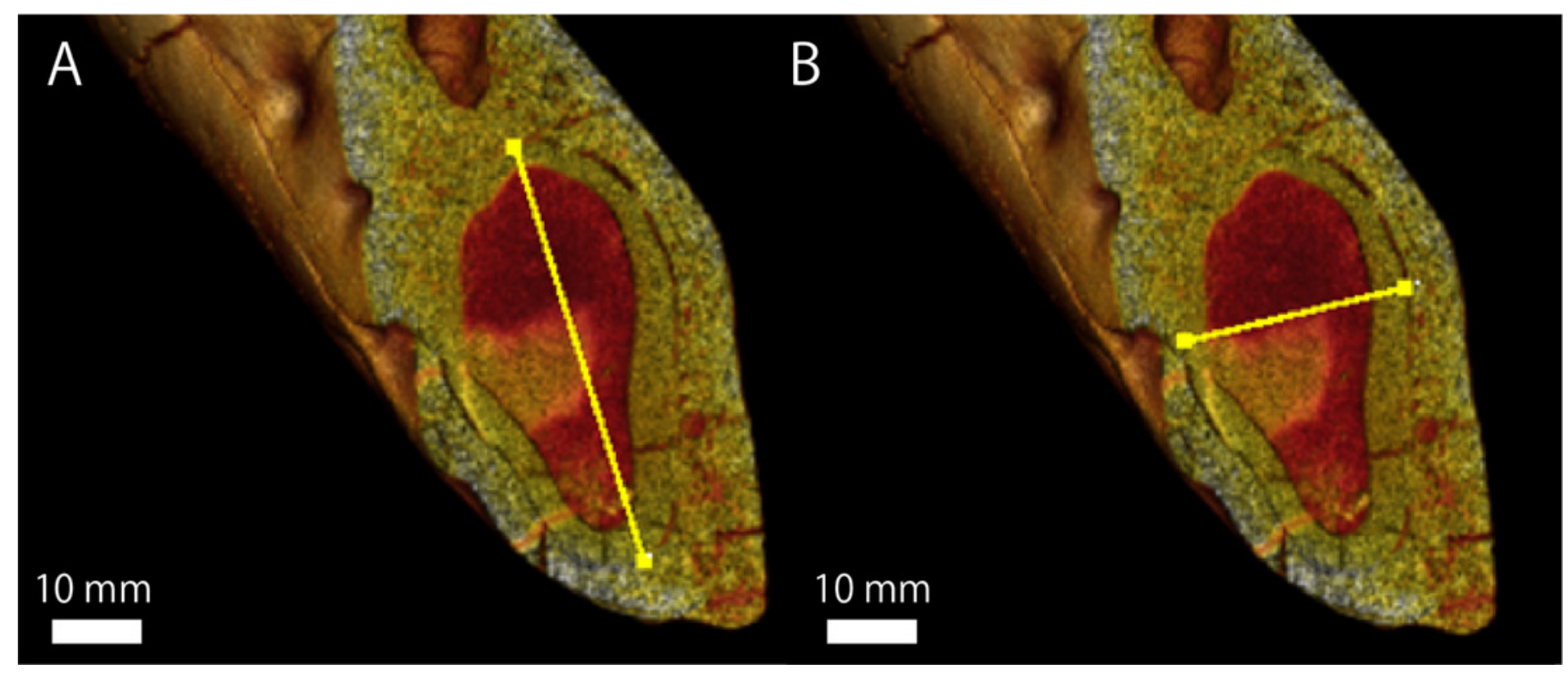


Figure 6

\section{Mandibular PCA results comparing PC1 and PC2}

Ovals represent 95\% confidence intervals for each group (species and sex).

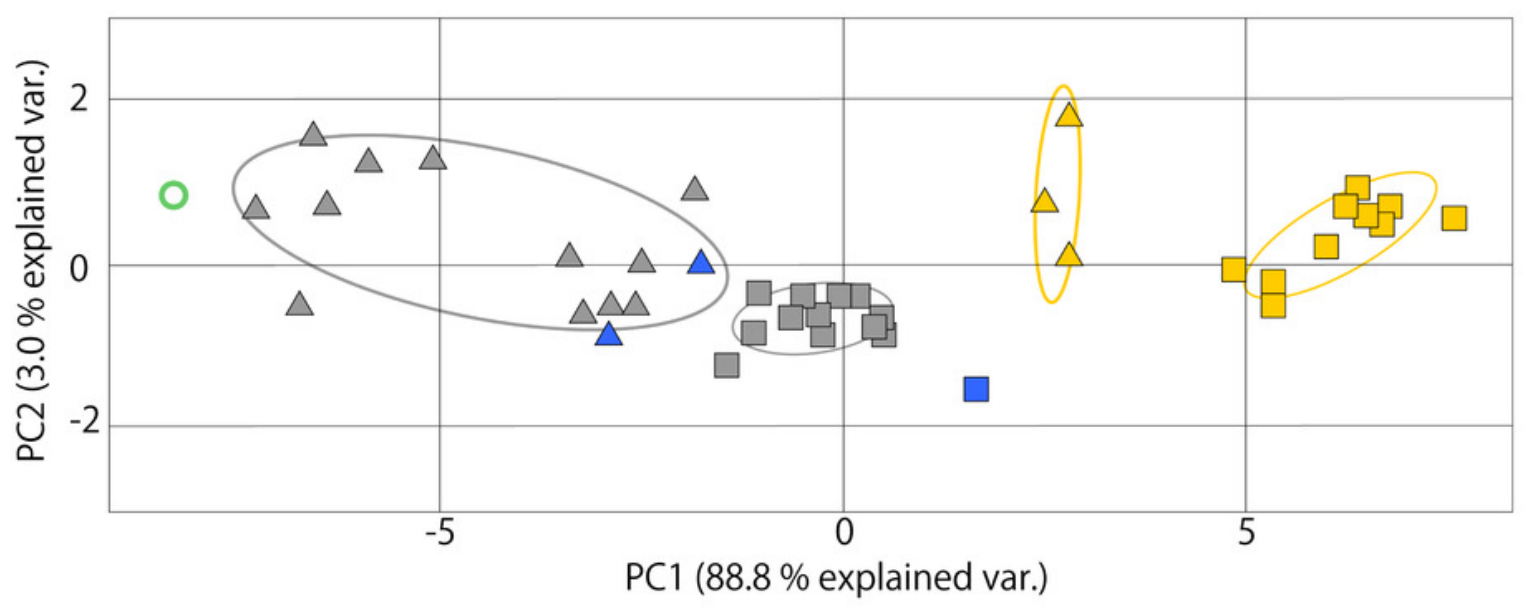
$\triangle$ E. jubatus [male]
E. jubatus [female]
$\triangle$ C. ursinus $[\mathrm{m}]$
C. ursinus $[\mathrm{f}]$
$\Delta$ Z. japonicus $[\mathrm{m}]$
Z.japonicus [f]
○ GKZ-N 00001 
Figure 7

Postcanine roots by $\mathrm{CT}$ image

(A) GKZ-N 00001 (B) E. jubatus (NMNS-KK 14)

Photo credits: (A) Naoki Kohno (B) Chisako Sakata
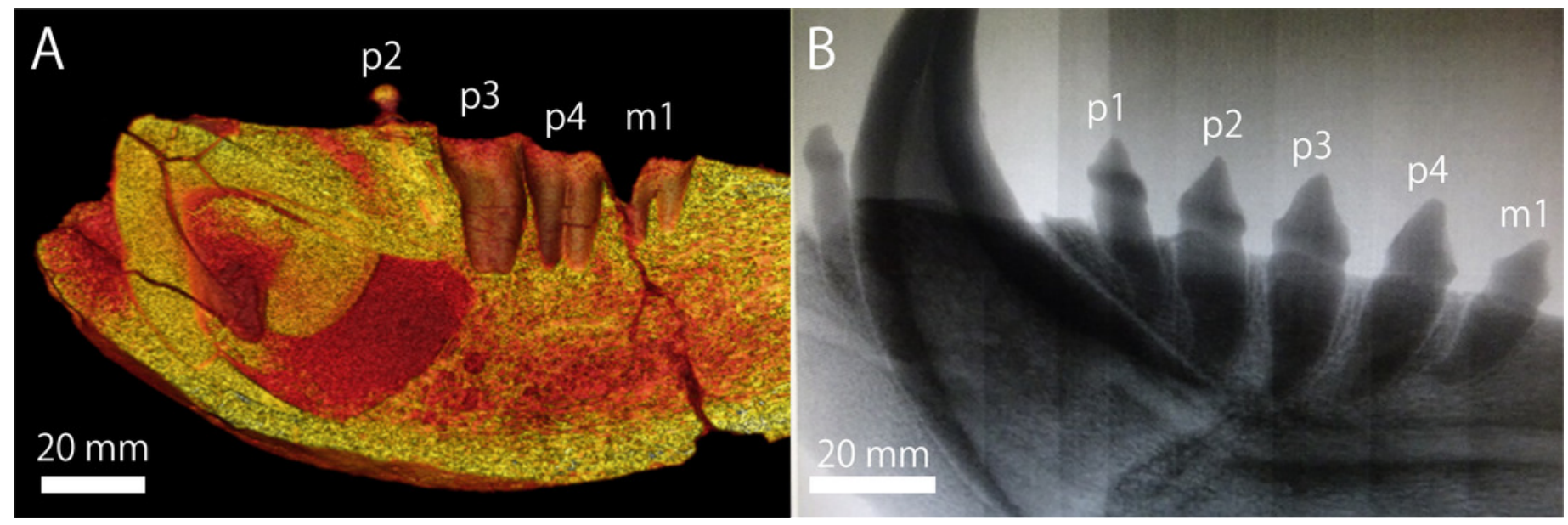
Table $\mathbf{1}$ (on next page)

Sample list 


\begin{tabular}{|c|c|c|l|}
\hline Scientific name & Sex & N & Registration number \\
\hline $\begin{array}{c}\text { Eumetopias } \\
\text { jubatus }\end{array}$ & male & 12 & NMNS-KK14,15,23,51,63,69,73,167,169,192,NSMT-M5627,28387 \\
\cline { 2 - 5 } & female & 12 & NMNS-KK11,53,54,55,56,139,146,154,158,165,166,NSMT-M17123 \\
\hline $\begin{array}{c}\text { Callorhinus } \\
\text { ursinus }\end{array}$ & male & 3 & NSMT-M2454,46874,17140 \\
\cline { 2 - 5 } & female & 10 & NMNS-KK05,08,10,22,24,141,151,NSMT-M42128,35148,1995 \\
\hline $\begin{array}{c}\text { Zalophus } \\
\text { japonicus }\end{array}$ & male & 10 & HM-55953-18-1 8 / DCIFC-ER11H,-HM2L \\
\cline { 2 - 5 } & female & 1 & DCIFC-HM2 $\cdot 97 \mathrm{R}$. No.30262 \\
\hline $\begin{array}{c}\text { Proterozetes } \\
\text { ulysses }\end{array}$ & male & 2 & $\begin{array}{l}\text { USNM 187109 (Barnes et al., 2006), } \\
\text { UCMP 219377 (Poust \& Boessenecker, 2017) }\end{array}$ \\
\hline
\end{tabular}




\section{Table 2 (on next page)}

Mandibular landmarks used in this study 


\begin{tabular}{|l|l|}
\hline 1 & rostral tip of mandible (gnathion) \\
\hline 2 & caudal-most point of mandibular condyle \\
\hline 3 & lateral edge of canine midpoint \\
\hline 4 & medial edge of mandibular symphysis caudal to the first incisor \\
\hline 5 & ventral edge of mandible underneath the canine \\
\hline 6 & lateral and caudal edge of last postcanine \\
\hline 7 & ventral edge of mandible underneath the last postcanine \\
\hline 8 & lateral and caudal edge of p1 \\
\hline 9 & ventral edge of mandible underneath the p1 \\
\hline 10 & lateral-most point of mandibular condyle \\
\hline 11 & medial-most point of mandibular condyle \\
\hline 12 & dorsal-most point of coronoid process (koronion) \\
\hline 13 & ventral edge of mandible underneath the tip of the coronoid process \\
\hline 14 & caudal-most point of coronoid process \\
\hline 15 & rostral point horizontal to caudal-most point of coronoid process \\
\hline 16 & rostral start point of the coronoid process \\
\hline 17 & rostral-most point on curving edge of coronoid process \\
\hline 18 & caudal-most point on curving edge of coronoid process \\
\hline 19 & dorsal tip of canine \\
\hline 20 & ventral edge of mandible underneath the start of the coronoid process \\
\hline 21 & lateral and caudal edge of canine \\
\hline
\end{tabular}




\section{Table 3(on next page)}

Measurements (in $\mathrm{mm}$ ) of GKZ-N 00001 for morphometric analyses

The numbers in parentheses correspond to each landmark. 


\begin{tabular}{|l|r|}
\hline rostral tip of mandible- ventral edge of mandible underneath the canine (1-5) & 50.35 \\
\hline width of mandible (3-4) & 42.76 \\
\hline depth of ramus at c1(5-21) & 75.15 \\
\hline depth of ramus at p1(8-9) & 76.46 \\
\hline depth of ramus at m1 (6-7) & 66.34 \\
\hline ventral edge of mandible underneath the canine-ventral edge of mandible underneath the last & 100.13 \\
postcanine (5-7) & \\
\hline lateral and caudal edge of last postcanine-rostral start point of the coronoid process (6-16) & 27.60 \\
\hline major axis of mandibular symphysis & 81.31 \\
\hline minor axis of mandibular symphysis & 50.29 \\
\hline major axis of masseteric fossa & 68.43 \\
\hline minor axis of masseteric fossa & 45.73 \\
\hline depth of masseteric fossa & 13.18 \\
\hline tooth length & 123.89 \\
\hline cheek tooth length $\square$ & 84.03 \\
\hline transverse width of c1 & 27.32 \\
\hline mesiodistal diameter of c1 & 35.00 \\
\hline anteroposterior length of p1 & 13.33 \\
\hline anteroposterior length of p2 & 12.79 \\
\hline anteroposterior length of p3 & 16.07 \\
\hline anteroposterior length of p4 & 14.51 \\
\hline anteroposterior length of m1 & 18.42 \\
\hline diastema length between c1 and p1 & 10.04 \\
\hline
\end{tabular}




\section{Table 4 (on next page)}

Comparisons of measurements of the lower canines between the E. jubatus and GKZ-N 00001

MR: greatest mesiodistal diameter of the root BR: greatest buccolingual diameter of the root $(9+)=$ over 9 years old (age determination is based on Kubota et al., 1961) 


\begin{tabular}{|l|l|l|l|}
\hline & $\mathrm{N}$ & Min-Max & $\mathrm{Mn}$ \\
\hline E. jubatus :Male (Kohno \& Tomida, 1993) & & & \\
\hline $\mathrm{MR}(9+)(\mathrm{mm})$ & 4 & $38.6-42.4$ & 39.1 \\
\hline $\mathrm{BR}(9+)(\mathrm{mm})$ & 4 & $21.4-22.6$ & 21.8 \\
\hline $\mathrm{BR} / \mathrm{MR} \times 100(\%)$ & 4 & $51.6-61.8$ & 56.6 \\
\hline GKZ-N 00001 (this study) & & & \\
\hline $\mathrm{MR}(\mathrm{mm})$ & 1 & 50.3 & \\
\hline $\mathrm{BR}(\mathrm{mm})$ & 1 & 27.6 & \\
\hline $\mathrm{BR} / \mathrm{MR} \times 100(\%)$ & 1 & 54.9 & \\
\hline
\end{tabular}

